Brazilian Journal

of Chemical

ISSN 0104-6632

Engineering

\title{
SEPARATION OF L-TRYPTOPHAN PRESENT IN AN AROMATIC AMINO ACIDS MIXTURE IN A FOUR-COLUMN SIMULATED MOVING BED: EXPERIMENTAL AND SIMULATION STUDIES
}

\author{
M. A. Cremasco ${ }^{1 *}$, A. Starquit ${ }^{1}$ and N.-H. L. Wang ${ }^{2}$ \\ ${ }^{1}$ School of Chemical Engineering, State University of Campinas, \\ 13083-970, Campinas - SP, Brazil. \\ E-mail: cremasco@feq.unicamp.br \\ ${ }^{2}$ School of Chemical Engineering, Purdue University, \\ West Lafayette - IN, 47907-1283, USA.
}

(Submitted: April 12, 2007 ; Revised: February 20, 2008 ; Accepted: March 22, 2008)

\begin{abstract}
An experimental and theoretical study is presented for the fractionation of L-Tryptophan (Trp) from L-phenylalanine (Phe) and L-tyrosine (Tyr). A Simulated-Moving Bed (SMB) with four-column system was tested, and the results are presented as effluent histories of the raffinate and extract ports. L-phenylalanine and L-tyrosine were recovered as major products in the raffinate, while L-Tryptophan was recovered at the extract. To simulate the L-Tryptophan separation, a general rate model was used to represent the mass transfer phenomena that occur in each individual column of the SMB, for each solute present in the multicomponent system. A hybrid method was used to solve the model. An analytic solution was used for the intra-particle concentration, and was correlated to the liquid bed concentration by Duhamel's theorem. The results from simulation are compared with the experimental data presented in this work.

Keywords: Simulated-Moving Bed; Amino Acids; Triptophan.
\end{abstract}

\section{INTRODUCTION}

Among twenty amino acids found universally in proteins, L-Phenylalanine (Phe), L-Tyrosine (Tyr), and L-Tryptophan (Trp) are classified as aromatic amino acids due to presence of benzenic ring in their structures. These amino acids are important in the synthesis of several biologically active amines, for example, in $\beta$-endorphin, a neurotransmitter (Bohinski, 1987). L-Tryptophan, Figure 1, is an essential amino acid, that presents as chemical formula $\mathrm{C}_{11} \mathrm{H}_{12} \mathrm{~N}_{2} \mathrm{O}_{2}$, and molecular mass equal to $204.23 \mathrm{~g} / \mathrm{mol}$. It cannot be synthesized by the organism and therefore must be part of its diet. LTryptophan is a precursor for serotonin, melatonin, and niacin. Trp has been implicated as a possible cause of schizophrenia in people who cannot metabolize it properly. When improperly metabolized, it creates a waste product in the brain that is toxic, causing hallucinations and delusions. L-Tryptophan has then been indicated as an aid for schizophrenic patients.<smiles>N[C@H](Cc1c[nH]c2ccccc12)C(=O)O</smiles>

Figure 1: Triptophan chemical structure formulae.

*To whom correspondence should be addressed 
Amino acids are separated usually by batch ionexchange chromatography (Dechow,1989). But, studies show that it is possible to get more production, more recovery, and solutes purities using continuous contact systems, such as SimulatedMoving Bed (SMB). In the SMB system it is possible to separate similar solutes with low solvent consumption and high sorbent utilization. The SMB application to amino acid separation can be found in the Hashimoto et al. (1989) paper, where they present a SMB unity with three zones to separate $\mathrm{NaCl}$ and Phe on Amberlite XAD-7 resin. The Wu et al. (1998) work shows the Phe and Trp separation on poly-4-vinylpyridine (PVP) resins in a large-scale SMB system with four zones. Using the same system than $\mathrm{Wu}$ et al. (1998), Cremasco et al. (2000) showed the separation of Phe and Tyr.

In a traditional SMB system, a series of fixed bed columns is connected to form a circuit. This circuit is divided into four zones by two inlet ports (feed and a solvent) and two outlet ports (a raffinate port, where the low-affinity mixture A is removed, and an extract port, where a high-affinity mixture B is removed). The inlet and outlet ports are periodically moved along the solvent flow direction by multiple-position valves, causing an apparent countercurrent movement between the liquid and the solid phase.

As in batch chromatography, mixture A migrates faster than solute $\mathrm{B}$ in the liquid flow direction. In this work, experimental run with pulse test was used to check this information. If the average feed port velocity is lower than the mixture A migration velocity and larger than mixture $\mathrm{B}$ migration velocity, then A will have a net velocity in the solvent flow direction relative to the feed port, while B will have a net velocity in the opposite direction. In this case, the standing wave theory says that mixture A adsorption wave remains stationary in zone IV, while its desorption wave stands in zone II. Solute B adsorption wave lies in zone III, and its desorption wave stands in zone $\mathrm{I}$, as represented in Figure 2 (Cremasco and Wang, 2000). In this Figure, A, means low-affinity mixture; B, high-affinity mixture; D means solvent flow; E, extract flow; F, feed flow; and R, raffinate flow.

Despite many advantages of the SMB system, its design depends on the appropriate choice of the four zones flow rates, four zones lengths, and the port movement velocity, which depends on switching time. In the case of multicomponent system, another important question appears: how to split the focused solute from the others? In case of three components, Cremasco and Wang (2000), in their theoretical study, showed that this is possible choosing the selectivity among them. In this paper, an experimental study is presented for the fractionation of Trp, from Phe and Tyr. The choice of these amino acids lies in their similarity, especially the close affinity between Phe and Tyr for the resin used in this work.

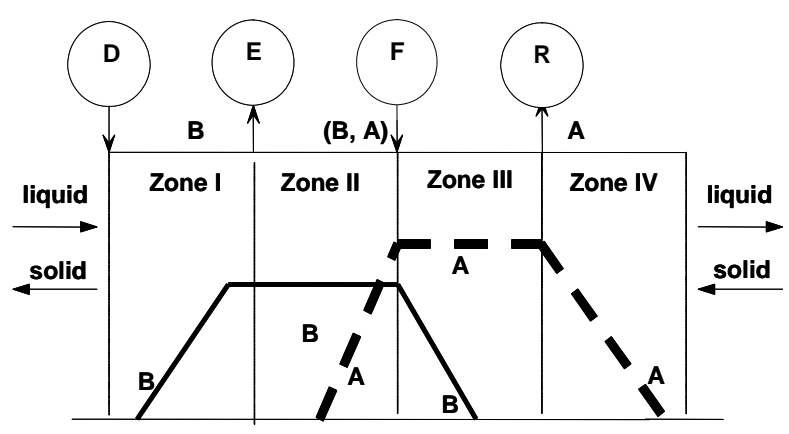

Figure 2: Pseudo-binary strategy of separation on the multicomponent system.

\section{THEORY}

In order to construct a mathematical model for the representation of the adsorption phenomena that take place in The Simulated-Moving Bed, some considerations must be made. In the present work those assumptions are: (Cremasco et al., 2003):

- liquid flow rates are constant and cross section is uniform;

- liquid concentration profile varies very little with bed radial position;

- axial dispersion effects are considered, with a constant dispersion coefficient;

- external mass transfer resistance from the bulk liquid to the resin is assumed to be very small $(\mathrm{Bi} \rightarrow \infty)$;

- solid phase (resin) is composed of small spheres of uniform radius;

- the mobile phase is a dilute solution, so that Henry's law can be used to describe the sorbate uptake;

- intraparticle transport is described by pore diffusion. For a linear isotherm system, the flux due to surface diffusion, if important, can be lumped with the pore diffusion flux;

- no chemical reaction occurs;

- initial concentration inside the column (liquid and resin) is zero.

Based on the previous hypotheses, the adsorption process can be described by the following set of equations, for each solute in each column (Cremasco et al., 2003): 
Solid Phase

$\varepsilon_{\mathrm{p}} \cdot \frac{\partial \mathrm{q}_{\mathrm{j}}^{\mathrm{i}}}{\partial \mathrm{t}}+\left(1-\varepsilon_{\mathrm{p}}\right) \cdot \frac{\partial \mathrm{C} \mathrm{p}_{\mathrm{j}}^{\mathrm{i}}}{\partial \mathrm{t}}=\varepsilon_{\mathrm{p}} \cdot \mathrm{D}_{\mathrm{P}}^{\mathrm{j}} \cdot \frac{1}{\mathrm{r}^{2}} \cdot \frac{\partial}{\partial \mathrm{r}}\left(\mathrm{r}^{2} \cdot \frac{\partial \mathrm{q}_{\mathrm{j}}^{\mathrm{i}}}{\partial \mathrm{r}}\right)$

$\mathrm{Cp}_{\mathrm{j}}^{\mathrm{i}}=\mathrm{k}_{\mathrm{p}}^{\mathrm{j}} \cdot \mathrm{q}_{\mathrm{j}}^{\mathrm{i}}$

where $\mathrm{q}$ is the solute concentration in the liquid phase inside the particle pores (volume fraction $\left.\varepsilon_{\mathrm{p}}\right), \mathrm{Cp}$ is the solute concentration on the solid (volume fraction $1-\varepsilon_{\mathrm{p}}$ ), and indices, $\mathrm{i}$ and $\mathrm{j}$, refer to column and solute, respectively (Cremasco et al., 2003):

Fluid Phase

$$
\frac{\partial C_{j}^{i}}{\partial t}=E_{b j} \cdot \frac{\partial^{2} C_{j}^{i}}{\partial z^{2}}-u^{i} \cdot \frac{\partial C_{j}^{i}}{\partial z}-R a_{j}^{i}
$$

where $\mathrm{C}$ is the solute concentration in the fluid phase (volume fraction $\varepsilon$ ), and $\mathrm{Ra}$ is the rate of adsorption/desorption of solute by the solid, by reactor volume unit, which is expressed as

$$
\begin{aligned}
& \mathrm{Ra}_{\mathrm{j}}^{\mathrm{i}}=\frac{1-\varepsilon}{\varepsilon} \cdot \frac{3}{\mathrm{R}^{3}} . \\
& \frac{\partial}{\partial \mathrm{t}}\left\{\int_{0}^{\mathrm{R}}\left[\varepsilon_{\mathrm{p}} \cdot \mathrm{q}_{\mathrm{j}}^{\mathrm{i}}+\left(1-\varepsilon_{\mathrm{p}}\right) \cdot \mathrm{C} \mathrm{p}_{\mathrm{j}}^{\mathrm{i}}\right] \cdot \mathrm{r}^{2} \cdot \mathrm{dr}\right\}
\end{aligned}
$$

Using Eq. (2) in Eqs. (1) and (4) results in:

$$
\begin{aligned}
& {\left[\varepsilon_{\mathrm{p}}+\left(1-\varepsilon_{\mathrm{p}}\right) \cdot \mathrm{k}_{\mathrm{p}}^{\mathrm{j}}\right] \cdot \frac{\partial \mathrm{q}_{\mathrm{j}}^{\mathrm{i}}}{\partial \mathrm{t}}=\varepsilon_{\mathrm{p}} \cdot \mathrm{D}_{\mathrm{P}}^{\mathrm{j}} \cdot\left(\frac{2}{\mathrm{r}} \cdot \frac{\partial \mathrm{q}_{\mathrm{j}}^{\mathrm{i}}}{\partial \mathrm{r}}+\frac{\partial^{2} \mathrm{q}_{\mathrm{j}}^{\mathrm{i}}}{\partial \mathrm{r}^{2}}\right)} \\
& \mathrm{Ra}_{\mathrm{j}}^{\mathrm{i}}=\frac{1-\varepsilon}{\varepsilon} \cdot \frac{3}{\mathrm{R}^{3}} \cdot\left[\varepsilon_{\mathrm{p}}+\left(1-\varepsilon_{\mathrm{p}}\right) \cdot \mathrm{k}_{\mathrm{p}}^{\mathrm{j}}\right] \cdot \frac{\partial}{\partial t}\left\{\int_{0}^{\mathrm{R}} \mathrm{q}_{\mathrm{j}}^{\mathrm{i}} \cdot \mathrm{r}^{2} \cdot \mathrm{dr}\right\}(6)
\end{aligned}
$$

The initial and boundary conditions that describe the adsorption process are expressed as follows:

$$
\begin{array}{ll}
\frac{\partial C_{j}^{i}}{\partial z}=\frac{u^{i}}{E_{b j}^{i}} \cdot\left(C_{j}^{i}-C_{0 j}^{i}\right) & \text { for } z=0 \\
C_{j}^{i}=q_{j}^{i}=0 & \text { for } t=0
\end{array}
$$

where $\mathrm{C}_{0}$ is the solute concentration in the column inlet flow. Note that this concentration is not constant, but depends on the system evolution.

$$
\frac{\partial \mathrm{C}_{\mathrm{j}}^{\mathrm{i}}}{\partial \mathrm{z}}=0 \quad \text { for } \mathrm{z}=\mathrm{L}_{\mathrm{C}}
$$

$\frac{\partial q_{j}^{i}}{\partial r}=0 \quad$ for $r=0$

$$
\mathrm{q}_{\mathrm{j}}^{\mathrm{i}}=\mathrm{C}_{\mathrm{j}}^{\mathrm{i}} \quad \text { for } \mathrm{r}=\mathrm{R}
$$

Note that Eq. (11) can be written in this simplified form, since, in this work, $\mathrm{Bi} \rightarrow \infty$ is assumed. Most of the parameters necessary for the simulations were estimated by the use of relations from the literature. The axial dispersion coefficient can be calculated from (Athalye et al., 1992):

$\frac{E_{b}}{u \cdot R}=2 \cdot\left(\frac{\mathrm{Pe}_{M_{P}}}{1-\varepsilon}\right)^{1 / 6}$

with the molecular mass Peclet number for a particle defined by

$$
\mathrm{Pe}_{\mathrm{Mp}}=\frac{2 \cdot \text { R.u. } \varepsilon_{\mathrm{p}}}{\mathrm{D}_{\mathrm{AB}}}
$$

\section{NUMERICAL SIMULATION}

The numerical method developed in this work is an adaptation of a hybrid method presented before (Cremasco et al., 2003), and permits to describe breakthrough curves of single low concentration adsorbable component. The intra-particle liquid solute concentration is found analytically, and correlated to the liquid bed concentration through Duhamel's theorem. Nonetheless, the bed concentration is obtained numerically. The use of Duhamel's theorem results in an equation connecting the intra-particle liquid concentration, $\mathrm{q}$, to the liquid bed concentration, C. This correlation is expressed as:

$$
\mathrm{q}_{j}^{\mathrm{i}}=\int_{0}^{\mathrm{t}}\left[-\frac{\partial \theta^{\mathrm{j}}(\mathrm{r}, \mathrm{t}-\tau)}{\partial \tau}\right] \cdot \mathrm{C}_{\mathrm{j}}^{\mathrm{i}} \cdot \mathrm{d} \tau
$$


where $\theta$ is the dimensionless solution of the problem established by Eq. (5), initial condition (8), and boundary conditions (10) and (11); t, is time, and $\tau$, the integrating variable. However, in order to express $\mathrm{Ra}$, it is more convenient to use the average concentration, $\bar{\theta}$, defined as (Cremasco, 2002)

$\bar{\theta}^{\mathrm{j}}(\mathrm{t})=\frac{3}{\mathrm{R}^{3}} \cdot \int_{0}^{\mathrm{R}} \theta^{\mathrm{j}}(\mathrm{r}, \mathrm{t}) \cdot \mathrm{r}^{2} \cdot d r$

Substituting the analytic solution into the previous equation results in Eq.(13):

$$
\bar{\theta}^{j}=1-\frac{6}{\pi^{2}} \cdot \sum_{n=1}^{\infty} \frac{1}{n^{2}} \cdot \exp \left(-n^{2} \cdot . \pi^{2} \cdot F o_{M}{ }^{j}\right)
$$

where the modified Fourier-mass number is

$$
\mathrm{Fo}_{\mathrm{M}}{ }^{\mathrm{j}}=\frac{\varepsilon_{\mathrm{p}}}{\left[\varepsilon_{\mathrm{p}}+\left(1-\varepsilon_{\mathrm{p}}\right) \cdot \mathrm{k}_{\mathrm{p}}^{\mathrm{j}}\right]} \cdot \frac{\mathrm{D}_{\mathrm{P}}^{\mathrm{j}} \mathrm{t}}{\mathrm{R}^{2}}
$$

Introducing Eqs. (14) and (16) in Eq. (6), results in:

$$
\begin{aligned}
& \operatorname{Ra}_{j}^{i}=\frac{1-\varepsilon}{\varepsilon} \cdot\left[\varepsilon_{p}+\left(1-\varepsilon_{p}\right) \cdot k_{p}^{j}\right] . \\
& \frac{\partial}{\partial t}\left\{\left.\int_{0}^{t} \frac{d \bar{\theta}^{j}(\xi)}{d \xi}\right|_{\xi=t-\tau} \cdot C_{j}^{i}(z, \tau) \cdot d \tau\right\}
\end{aligned}
$$

This expression is introduced into Eq. (3), which is numerically solved by a first-order discretization method. As a result, some linear tridiagonal sets of equations have to be solved, which is accomplished using the Thomas algorithm.

Considering the physical process, old concentrations in the column would not influence the rate of adsorption at the actual time. Mathematically, the derivative in Eq. (18) tends to zero when $\tau$ tends to zero. For this reason, the integral in Eq.(18) is estimated using calculated values from the beginning of the past switching period, until the actual time. This allows us to diminish the computing time and the memory used. Note also that at each switching there will be a change in the position of the columns in the system (zone), and that their boundary conditions are continuously changing.

\section{EXPERIMENTAL SECTION}

\section{Pulse Test}

The experimental set-up is illustrated in Figure 3. The system consists of two Pharmacia P-500 lowpressure pumps, a Pharmacia LCC-500 controller, and a Pharmacia MV-7 injection valve. For data acquisition a Waters 990 photodiode array detector was used, and the data were processed using the Waters 900 software. A Pharmacia glass column with a length of $12.5 \mathrm{~cm}$ and an internal diameter of $1.5 \mathrm{~cm}$ was used. The column was packed with Reillex $^{\mathrm{TM}}$ resin, which is poly-4-vinylpyridine crosslinked with divinylbenzene (PVP), purchased from Reilly Industries, Inc., Indianapolis, USA. The average particle diameter and average particle porosity are $0.036 \mathrm{~cm}$ and 0.55 , respectively. The PVP resin was chosen because it is physically stable and easy to regenerate.

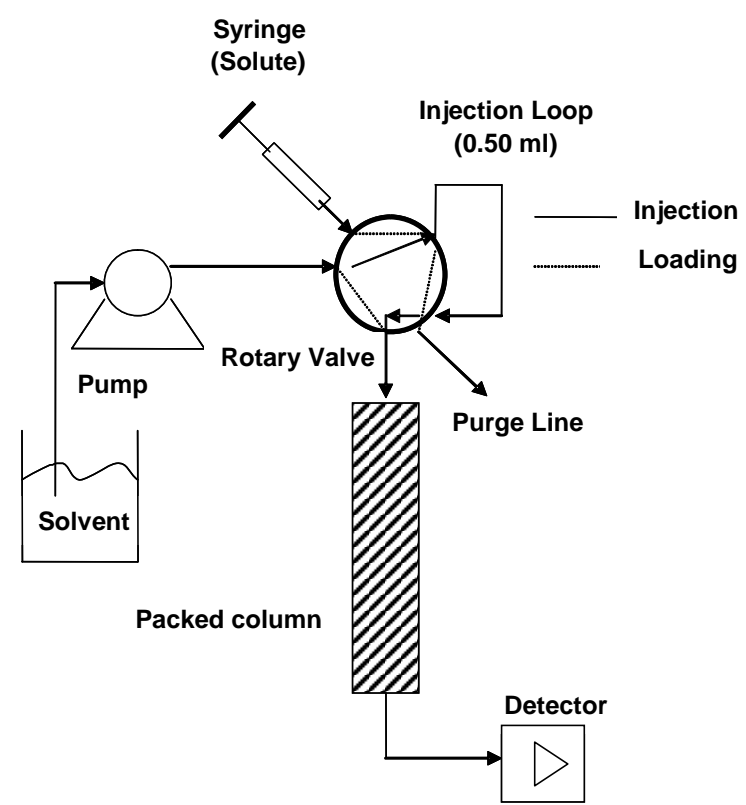

Figure 3: Fixed-bed experimental set-up for pulse tests.

Chromatographic elution curves were obtained using injection of small pulses $(0.50 \mathrm{ml})$ of aqueous solution of $2.0 \mathrm{~g} / 1$ of Phe, $0.35 \mathrm{~g} / \mathrm{l}$ of Tyr, and 0.35 $\mathrm{g} / \mathrm{l}$ of $\operatorname{Trp}$ respectively, where it is possible to guarantee the diluted system (Cremasco and Wang, 2000b). All experiments were performed at $1 \mathrm{~atm}$ and $25^{\circ} \mathrm{C}$. The solution was injected into the column using a rotary valve and an injection loop. The flow rate of the eluent was $1.5 \mathrm{ml} / \mathrm{min}$. The effluent was monitored in the ultraviolet wavelength range: 260 $\mathrm{nm}$ for Phe, $300 \mathrm{~nm}$ for Tyr, and $300 \mathrm{~nm}$ for Trp. 


\section{SMB Experiment}

A four-zone SMB system was tested. Each zone consisted of a single $1.5 \mathrm{~cm}$ I.D. $\times 12.5 \mathrm{~cm}$ column (Figure 4). The columns were packed with the same resin used on pulse experiments. Feed concentration of $0.4 \mathrm{~g} / \mathrm{l}$ was used for the dilute aqueous solutions of amino acids L-phenylalanine (Phe), L-tyrosine (Tyr), and L-Triptofan (Trp) on SMB experiment. The system utilizes six eight-port rotary valves, four manual shut-off valves, and four pumps.

The six rotary valves together determine the placement of the zones. Valve \#1 determines where the feed enters (the column in Zone III, Figure 2). Valve \#2 determines where the raffinate is drawn. Valve \#3 determines where the stream returns after the raffinate is drawn. Valve \#4 determines where the eluent enters. Valve \#5 determines where the extract outlet occurs. Valve \#6 determines where the recycle stream returns after the extract is drawn.

Isotherm constants and diffusion coefficients of Phe, Tyr, and Trp given by Cremasco and Wang (2000b) are listed in Table 1 . The mixture A is composed by Phe and Tyr, because they present less affinity with PVP resin, while Trp was chosen as mixture B (high affinity with PVP resin). A separation as presented in Figure 5 is expected.

The feed concentration of mixture $\mathrm{A}$ is $\mathrm{C}_{\mathrm{A}}{ }^{\mathrm{F}}=0.8 \mathrm{~g} / 1$, with $0.4 \mathrm{~g} / 1$ of each Phe and Tyr, and mixture $B$ (Trp) has a feed concentration of $\mathrm{C}_{\mathrm{B}}{ }^{F}=0.4 \mathrm{~g} / \mathrm{l}$. The flow rates and the switching times were obtained from the linear standing wave analysis (Cremasco and Wang, 2000b). The operating parameters are listed in Table 2.

Table 1: Linear isotherm parameters and diffusion coefficients (Cremasco and Wang, 2000b).

\begin{tabular}{|c|c|c|r|}
\hline Amino Acids & $\mathbf{k} \mathbf{p}$ & $\mathrm{D}_{\mathbf{p}} \times 10^{-4} \quad \mathrm{~cm}^{2} / \mathrm{min}:$ & $\mathrm{D}_{\mathrm{AB}} \times 10^{-4} \quad \mathbf{c m}^{2} / \mathrm{min}^{\prime}$ \\
\hline Phe & 1.947 & 1.020 & 4.24 \\
Tyr & 3.229 & 1.010 & 4.12 \\
Trp & 13.70 & 0.940 & 3.89 \\
\hline
\end{tabular}

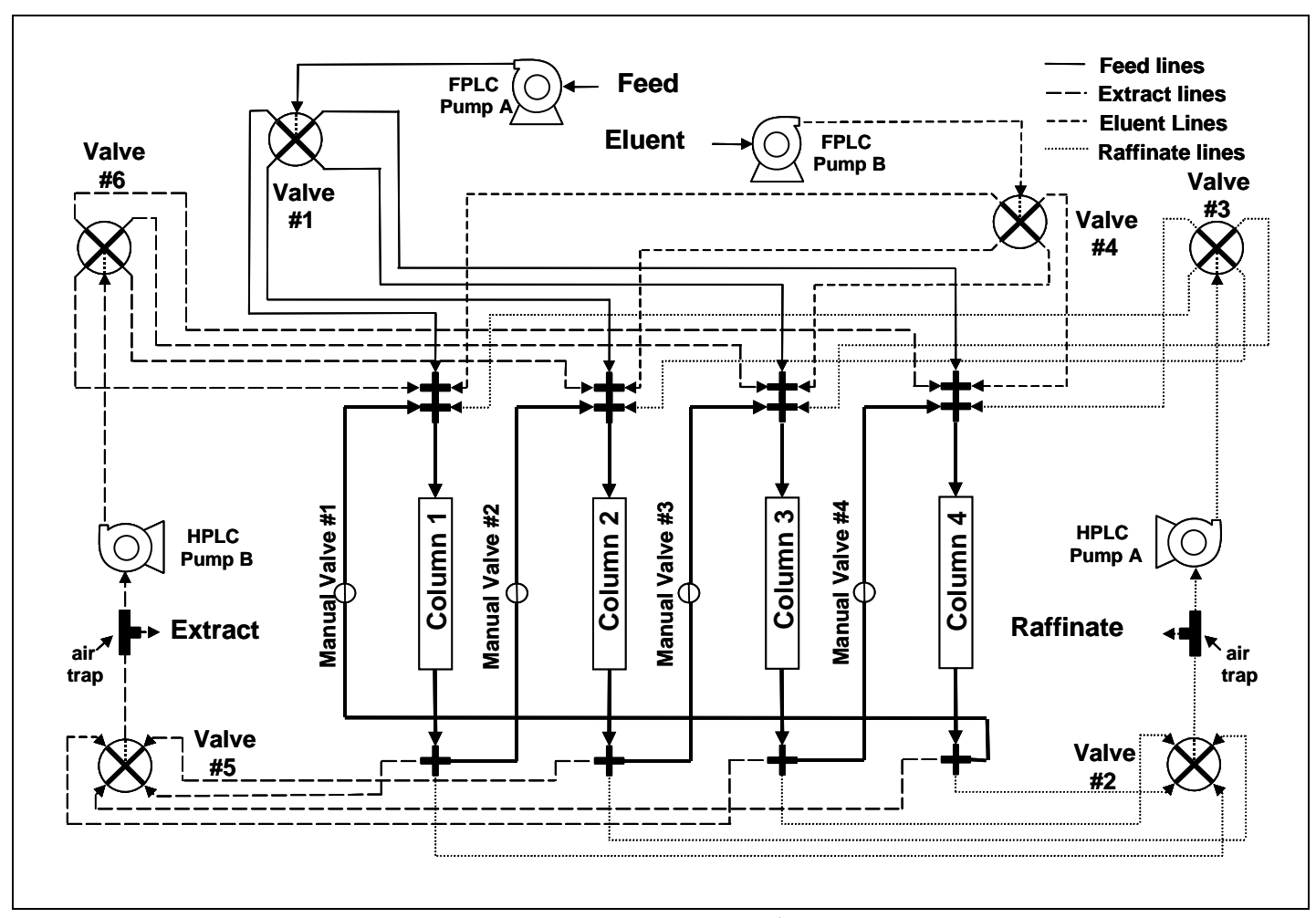

Figure 4: SMB apparatus: valves system. 


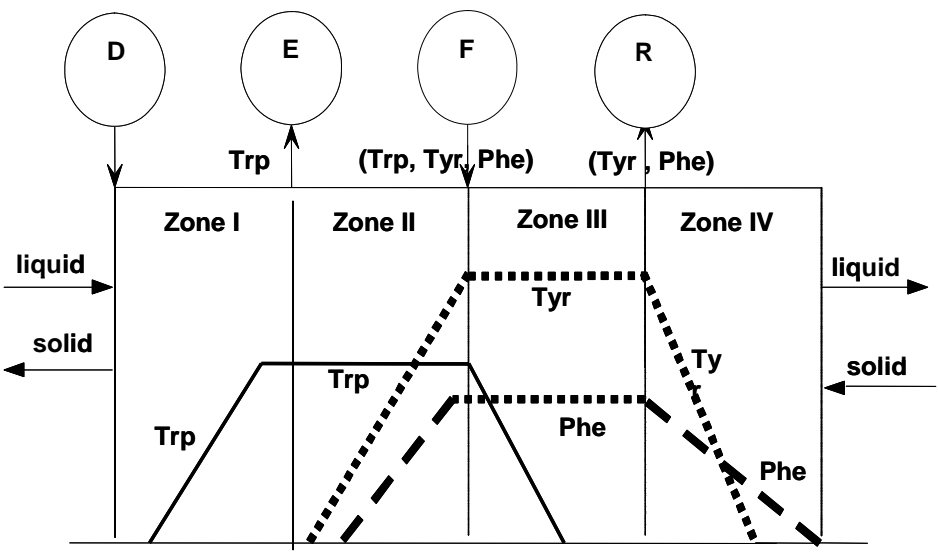

Figure 5: Strategy of separation of Trp from Phe and Tyr.

Table 2: SMB operating parameters (Cremasco and Wang, 2000b)

\begin{tabular}{|c|c|c|c|c|}
\hline $\mathbf{t}_{\text {switch }}$ ( $\left.\mathbf{m i n}\right)$ & $\mathbf{Q}^{\mathrm{I}}(\mathbf{m l} / \mathbf{m i n})$ & $\mathbf{Q}^{\mathrm{II}}(\mathbf{m l} / \mathbf{m i n})$ & $\mathbf{Q}^{\mathrm{III}}(\mathbf{m l} / \mathbf{m i n})$ & $\mathbf{Q}^{\mathrm{IV}}(\mathbf{m l} / \mathbf{m i n})$ \\
\hline 79.5 & 1.21 & 0.57 & 1.21 & 0.34 \\
\hline
\end{tabular}

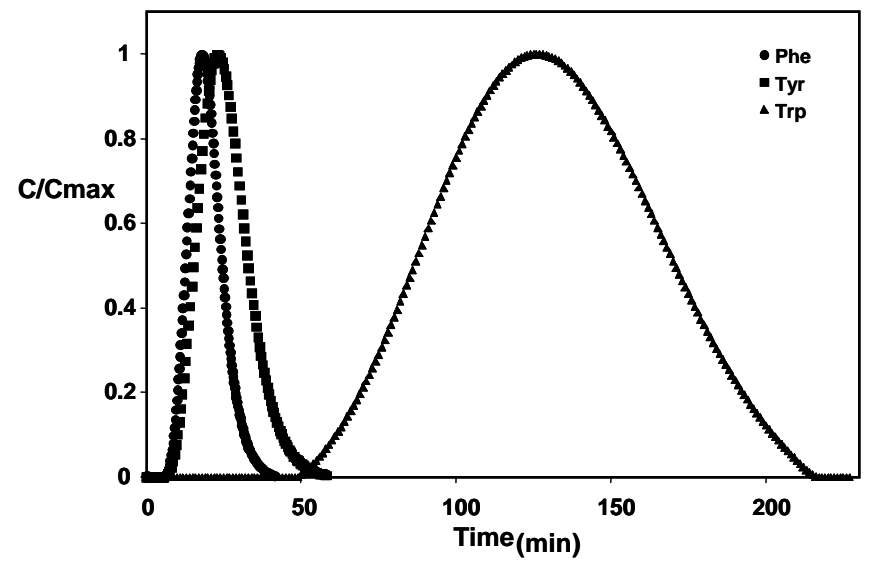

Figure 6: Experimental pulse tests.

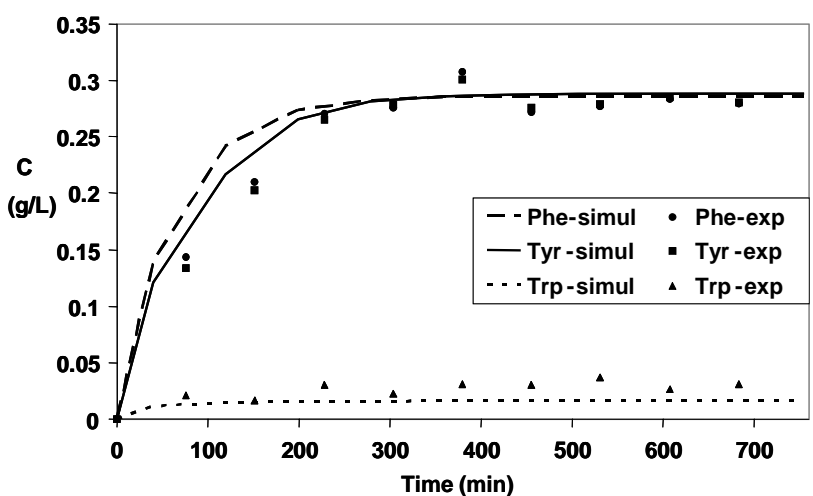

(a)

Figure 7 (a): Elution curves: Rafinatte

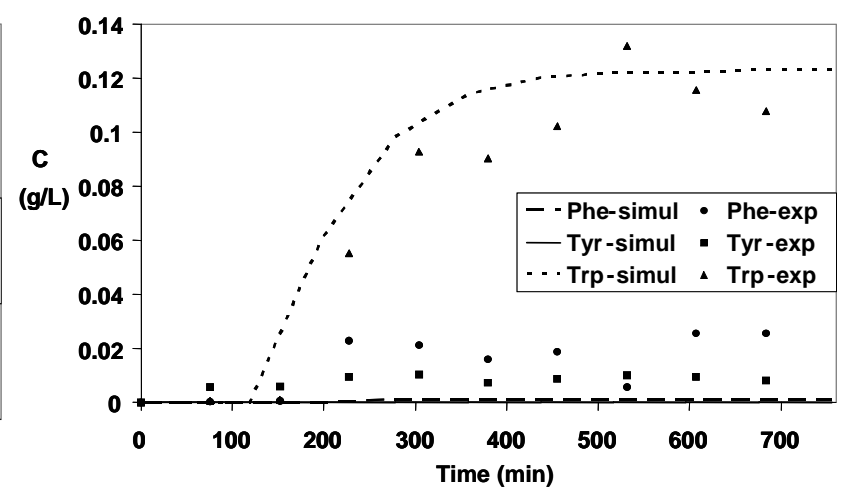

(b)

Figure 7 (b): Elution curves: Extract 


\section{RESULTS}

Figure 6 shows the results of amino acid experiment from pulse test. It is noticed that, as expected, Phe presents less affinity which PVP resin, and crosses the column faster than others amino acids, while Trp presents higher affinity, and crosses slower. When Figures 6 and 5 are compared, it is possible to verify that mixture A will migrate faster than mixture $\mathrm{B}$ in the liquid flow direction.

Figures $7 \mathrm{a}$ and $7 \mathrm{~b}$ present the simulation results and their comparison with the experimental values of the average effluent histories at raffinate and extract ports, respectively. Phe and Tyr are recovered as the major product at raffinate, while Trp is recovered at extract port. It is important to mention that the pump utilized in this experiment presented an error of $0.05 \mathrm{ml} / \mathrm{min}$. This could have affected zone IV, altering the flow rate at zone I, and at extract port, carrying out Phe and Tyr to the extract port, contaminating Trp. The further separation of Phe and Tyr from raffinate can be done using the same system shown at Figure 4, as presented at Cremasco et al. (2000) paper.

\section{CONCLUSION}

A laboratory-scale low-pressure SMB system with four zones and a single column in each zone has been tested for aromatic amino acids separation. From pseudo-binary mixture approach (Figure 1), it is possible to create a strategy to split the separation in case of ternary mixture (Figure 3). From the pulse test, it is possible to get an idea about the behavior of the migration of the mixture in the liquid flow direction (Figure 6).

The experimental results show a good separation at raffinate port, and reasonable separation at extract port. In this case, the contamination of Trp by Phe and Tyr, at extract port, may have been caused by the mechanical problem related with the pumps. The hybrid method for the numerical simulation of SMB outlet streams was tested and its results are compared with experimental data in this paper. This methodology offers satisfactory predictive results in a short time in comparison to the physical separation process as shown in this work. This implies that this method is adequate for separation predictions. The model utilized in this work is not absolutely general, since it is limited to the linear adsorption cases, with negligible external mass transfer resistance. Nonetheless, those model simplifications are commonly used in practice, whenever they are suitable.

\section{NOMENCLATURE}

C solute concentration in the mobile phase

$\mathrm{Cp} \quad$ superficial solid intra- $\mathrm{ML}^{3}$

$\mathrm{C}_{0} \quad$ column injection $\mathrm{ML}^{3}$

concentration

D column diameter L

$\mathrm{D}_{\mathrm{AB}} \quad$ free diffusion coefficient $\quad \mathrm{L}^{2} \mathrm{~T}^{-1}$

$\mathrm{D}_{\mathrm{p}} \quad$ effective diffusion $\quad \mathrm{L}^{2} \mathrm{~T}^{-1}$

coefficient

$\mathrm{E}_{\mathrm{b}} \quad$ axial dispersion coefficient $\quad \mathrm{L}^{2} \mathrm{~T}^{-1}$

$\mathrm{k}_{\mathrm{p}} \quad$ equilibrium partition

constant

$\mathrm{L}_{\mathrm{c}} \quad$ single column length $\mathrm{L}$

q intra-particle liquid phase $\mathrm{ML}^{3}$

$\mathrm{R}$ average particle radius $\mathrm{L}$

$t_{\mathrm{P}} \quad$ switching period $\quad \mathrm{T}$

u SMB liquid superficial $\quad \mathrm{LT}^{-1}$

\section{Greek Letters}

$\varepsilon \quad$ bed porosity $\quad(-)$

$\varepsilon_{\mathrm{p}} \quad$ particle porosity (-)

$\theta \quad$ dimensionless concentration (-)

\section{Subscripts}

E extract $\quad(-)$

F feed (-)

i zone i

j specie j (-)

$\mathrm{R} \quad$ raffinate $\quad(-)$

S solvent

I zone I $(-)$

II zone II

III zone III

$(-)$

IV zone IV

\section{REFERENCES}

Athalye, A. M., Gibbs, S. J., and Lightfoot, E. N., Predictability of Chromatographic Protein Separations: Study of Size-exclusion Media with Narrow Particle Size Distribution, J. Chrom., 589, p. 71 (1992). 
Bohinski, R. C., Modern Concepts in Biochemistry, $5^{\text {th }}$ Edition, Allyn and Bacon, Boston (1987).

Cremasco, M. A., Fundamentals of Mass Transfer (in Portuguese). $2^{\text {nd }}$ Edition. Unicamp Publisher, Campinas, Brazil (2002).

Cremasco, M. A., Hritzko, B. J. and Wang, N.-H. L, Separation of Two Amino Acids in a Fourcolumn Simulated Moving Bed: Experimental Study, Proceedings of XIII Brazilian Chemical Eng. Meeting, CD ROM, Águas de São Pedro, Brazil (2000).

Cremasco, M. A. and Wang, N.-H. L., Ternary Separation of Amino Acids in a Simulated Moving bed, Part I: Strategy of Design, Proceedings of XIV Chilean Chemical Eng. Congress, CD ROM, Santiago, Chile (2000).
Cremasco, M. A., Guirardello, R.and Wang, N.-H. L., Adsorption of Aromatic Amino Acids in a Fixed Bed Column, Braz. J. Chem. Eng., 20, No. 3, p. 327 (2003).

Dechow, F. J., Separation and Purification Techniques in Biotechnology, Noyes Publication, New Jersey (1989).

Hashimoto, K., Yamada, M. Adachi, S., Shirai, Y., A Simulated Moving-bed Adsorber with Three Zones for Continuous Separations of LPhenylalanine and $\mathrm{NaCl}$, J., Chem. Eng. of Japan, 22, No. 4, p. 432 (1989).

Wu, D.-J., Xie, Y., Ma, Z., and Wang, N.-H. L., Design of Simulated Moving Bed Chromatography for Amino Acids Separations, Ind. Eng. Chem. Res., 37, p. 4023 (1998). 